Engineering and Computational Mechanics Volume 166 Issue EM1

Non-linear analysis and moment redistribution of prestressed concrete members

Leung, Au and Kwan
Proceedings of the Institution of Civil Engineers

Engineering and Computational Mechanics 166 March 2013 Issue EM1 Pages 9-21 http://dx.doi.org/10.1680/eacm.11.00021

Paper 1100021

Received 30/09/2012

Published online 15/02/2013

Keywords: beams \& girders/buildings, structures \& design/concrete

structures

ICE Publishing: All rights reserved

\title{
Non-linear analysis and moment redistribution of prestressed concrete members
}

1 Cliff C. Y. Leung MSC

$\mathrm{PhD}$ candidate, Department of Civil Engineering, The University of Hong Kong, Hong Kong

2 Francis T. K. Au MSc, PhD, CEng, MICE, FIStructE, FHKIE Professor, Department of Civil Engineering, The University of Hong Kong, Hong Kong
3 Albert K. H. Kwan BSc, PhD, CEng, MICE, FHKIE Professor, Department of Civil Engineering, The University of Hong Kong, Hong Kong
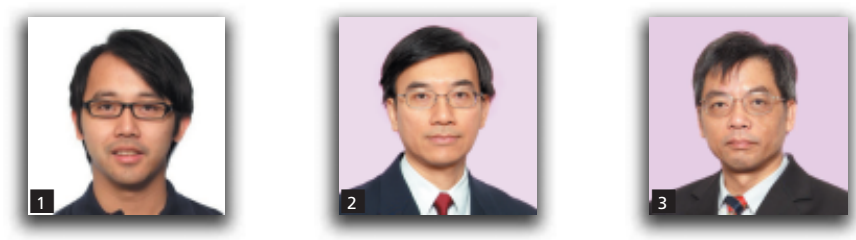

Most of the existing codes of practice allow moment redistribution to be applied to reinforced concrete design with upper limits of $20-30 \%$. It is, however, questionable whether the same limits are valid for the design of prestressed concrete members. Research in this area dates back to the 1950s, but investigations have mainly focused on the behaviour at different servicing limits and the effects of various parameters. Work has seldom been done on the effects of moment redistribution on structural safety, as the load-carrying capacity can be compromised with increase in moment redistribution owing to the limited ductility of concrete sections. In the present study, a method for nonlinear finite-element analysis is developed to examine the relationship between the reduction in load-carrying capacity and the moment redistribution applied to the design of prestressed concrete members, and how such a relationship is affected by section deformability and plastic hinge lengths. Results suggest that due care must be exercised when codified moment redistribution for prestressed concrete members is applied.

\section{Notation}

$a, b$

$\beta$

B

$\mathbf{B}_{1}$

$\mathbf{B}_{2}$

d

EI

$(E I)_{a},(E I)_{b}$ $(E A)_{a},(E A)_{b}$

f

$i$

$\mathbf{K}$

$\mathbf{K}_{\mathrm{e}}$

$\mathbf{K}_{\mathrm{g}}$

$L$

$l$

$l_{\mathrm{p}}$

M subscripts denoting nodes $a$ and $b$, respectively

amount of moment redistribution

strain matrix

flexural strain sub-matrix

axial strain sub-matrix

effective depth

flexural rigidity (taken as the slope of the initial elastic branch of the moment-

curvature curve)

flexural rigidities

axial stiffnesses

load vector

subscript denoting $i$ th load step

stiffness matrix

element stiffness matrix

global stiffness matrix

length of the element

span length

plastic hinge length

applied bending moment

\begin{tabular}{|c|c|}
\hline$M_{i}^{n}$ & $\begin{array}{l}\text { moment corresponding to the calculated } \\
\text { curvature } \phi_{i}^{n}\end{array}$ \\
\hline$M_{\mathrm{u}}$ & $\begin{array}{l}\text { design moment at a section obtained by } \\
\text { elastic analysis before redistribution is } \\
\text { prescribed }\end{array}$ \\
\hline$M_{\mathrm{u}}^{\prime}$ & $\begin{array}{l}\text { design moment at a section after } \\
\text { redistribution is prescribed }\end{array}$ \\
\hline$m_{i}^{n}$ & $\begin{array}{l}\text { moment calculated from the finite-element } \\
\text { analysis }\end{array}$ \\
\hline$N_{a}, N_{b}$ & shape functions \\
\hline$n$ & subscript denoting $n$th iteration step \\
\hline$P_{\mathrm{u}}^{\prime}$ & $\begin{array}{l}\text { load-carrying capacity of the beam designed } \\
\text { with prescribed moment redistribution }\end{array}$ \\
\hline$P_{\mathrm{u}}$ & $\begin{array}{l}\text { load-carrying capacities of the beam designed } \\
\text { without prescribed moment redistribution }\end{array}$ \\
\hline$w$ & imposed load \\
\hline$x$ & $x$-coordinate in the element axial direction \\
\hline$\gamma$ & reduction in load-carrying capacity \\
\hline$\Delta M$ & change in bending moment \\
\hline$\Delta w$ & change in imposed load \\
\hline$\Delta \varepsilon$ & fictitious incremental strain \\
\hline$\delta$ & displacement vector \\
\hline
\end{tabular}




$\begin{array}{ll}\lambda_{1}, \lambda_{2}, \lambda_{3}, m, n & \begin{array}{l}\text { parameters determined by regression from the } \\ \text { datasets of } \gamma \text { and } \beta\end{array} \\ \sigma_{\mathrm{m}} & \text { mean axial stress } \\ \phi & \text { section curvature } \\ \phi_{i}^{n} & \text { curvature at each element node at } n \text {th } \\ & \text { iteration step of } i \text { th load step } \\ \phi_{\mathrm{r}} & \text { residual curvature } \\ \left(\phi_{\mathrm{r}}\right)_{i}^{n+1} & \text { updated residual curvature }\end{array}$

\section{Introduction}

Moment redistribution as a tool in the design of continuous structural members is the arbitrary reduction in bending moments obtained by elastic analysis at the supports. This has been recognised as a practice leading to more economical designs. A maximum moment redistribution of $20-30 \%$ of the design elastic moment in reinforced concrete (RC) members is allowed by most design codes (ACI, 2005; BSI, 2004; Concrete Design Committee, 1995; CSA Technical Committee on Reinforced Concrete Design, 1994). Although many design codes allow moment redistribution in prestressed concrete (PC) members, it is doubtful if the same limits apply, as PC tends to be less ductile because of more reliance on compression.

The behaviour and effects of moment redistribution on RC and PC members have been studied previously (Cohn and Riva, 1992; do Carmo and Lopes, 2005, 2006; Lopes et al., 1997; Mattock, 1959; Priestley and Park, 1972; Scott and Whittle, 2005), but relatively little has been done on whether or not moment redistribution affects the load-carrying capacity of PC members. Although Mattock (1959), Scott and Whittle (2005) and do Carmo and Lopes (2006) have reviewed the effects of moment redistribution on the load-carrying capacity, their studies have mainly focused on RC rather than PC members.

Priestley and Park (1972) examined the moment redistribution of seven continuous PC beams. They developed a numerical method to predict the responses up to the peak load, and observed good agreement with the experimental results. The moment redistribution of partially prestressed continuous beams was examined experimentally by Lopes et al. (1997). They observed from seven specimens reduction down to $48 \%$ in elastic moment after redistribution, and considered that the allowable moment redistribution given in codes was conservative. However, the adverse effect of this amount of moment redistribution on structural performance is uncertain.

Regarding the lack of consensus on the allowable moment redistribution in RC members, do Carmo and Lopes (2006) found the allowable moment redistribution to depend on the plastic rotation capacity of critical sections, which was governed by the ratio of neutral axis depth at ultimate $x$ to effective depth $d$. Unlike Lopes et al. (1997), do Carmo and Lopes (2005) considered the codified allowable moment redistribution to be unsafe especially in cases of high $x / d$. Based on their numerical model, a series of empirical formulae were derived to predict the allowable moment redistribution based on the $x / d$ ratios.

In view of the limited ductility of RC and PC members, conventional plastic analysis assuming full plasticity is unrealistic and may overestimate the load-carrying capacity of the member. Therefore, a non-linear finite-element method for full-range analysis of PC members is developed to examine the effects of moment redistribution on the load-carrying capacity. As the extent to which PC members can undergo moment redistribution depends largely on the rotational capacity or deformability of the concrete section, a parametric study will be performed to investigate it.

\section{Method of analysis}

\subsection{General approach}

A PC member is modelled by beam elements whose constitutive behaviour is governed by the moment-curvature relationship of the sections at element nodes. Incremental load or displacement is then applied on which iterations are performed to obtain the admissible nodal displacements that satisfy the constitutive behaviour of each element. Unlike the previous technique adopted by Campbell and Kodur (1990) in which the moment-curvature relationship is based on the mid-section of an element, the present study is based on the moment-curvature relationship of the section at each nodal point. Apart from the more accurate modelling of varying tendon eccentricity within each element, the present formulation also avoids significant discontinuity of curvature across element boundaries. While Campbell and Kodur (1990) have adopted an iteration scheme using the secant flexural stiffnesses, an iteration scheme using the initial flexural stiffnesses and residual curvatures is devised so as to cope with not only loading beyond the peak resistance along the post-peak branch (i.e. continued increase in curvature) but also unloading before reaching the peak resistance. To a certain extent, the moment-curvature curve of a section depends on the axial load acting on the section, although such variations for a deck section are usually small. Nevertheless, the effect of axial load is taken into account by linear interpolation between moment-curvature curves corresponding to different prescribed mean axial stresses.

\subsection{Finite-element modelling and formulation}

The beam element used has two nodes, each with axial, lateral and rotational degrees of freedom. Flexural and axial deformations are first treated separately, while their interactions are considered afterwards. The flexural behaviour is governed by the moment-curvature relationship, which can be written as

$$
\text { 1. } M=E I\left(\phi-\phi_{\mathrm{r}}\right)
$$

where $M$ is the applied bending moment, $E I$ is the flexural rigidity that is taken as the slope of the initial elastic branch of the moment-curvature curve, and $\phi$ and $\phi_{\mathrm{r}}$ are the section curvature and the residual curvature, respectively. The constitu- 


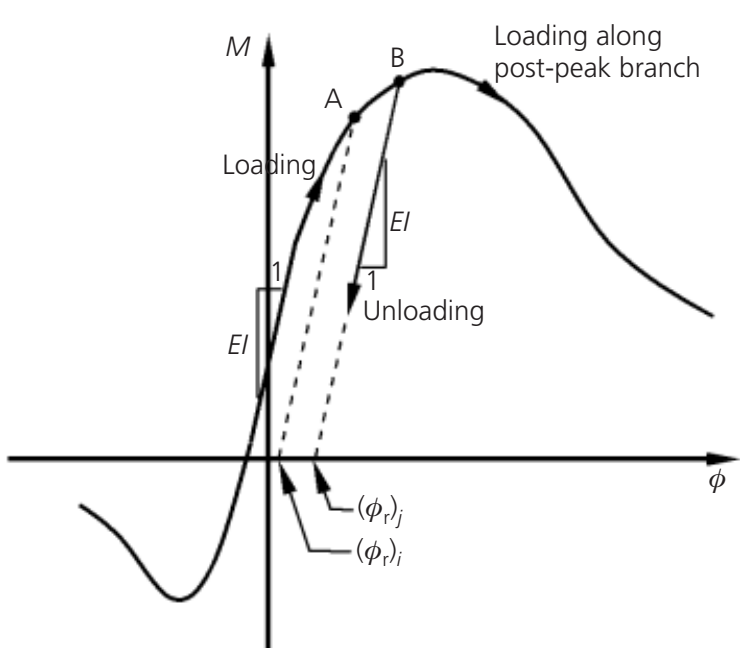

(a)



(b)

Figure 1. Constitutive model and iteration process in non-linear analysis: (a) constitutive model of beam section; (b) iteration process

tive model of a typical beam section is shown in Figure 1(a). The values of $E I$ and $\phi_{\mathrm{r}}$ within the element are interpolated linearly from those at nodes $a$ and $b$.

Derivation of the force-displacement relationship for each element using the potential energy approach gives the load vector $\mathbf{f}$ as

$$
\mathbf{f}=\mathbf{K} \boldsymbol{\delta}-\int \mathbf{B}_{\mathbf{1}}^{\mathrm{T}}\left[N_{a}(E I)_{a}+N_{b}(E I)_{b}\right]
$$

2.

$$
\times\left(N_{a} \phi_{r a}+N_{b} \phi_{r b}\right) \mathbf{B}_{1} \mathrm{~d} x
$$

where the stiffness matrix $\mathbf{K}$, the flexural and axial strain submatrices $\mathbf{B}_{1}$ and $\mathbf{B}_{2}$, and the shape functions $N_{a}$ and $N_{b}$ are given, respectively, as

$$
\begin{aligned}
\mathbf{K}= & \int \mathbf{B}_{1}^{\mathrm{T}}\left[N_{a}(E I)_{a}+N_{b}(E I)_{b}\right] \mathbf{B}_{1} \mathrm{~d} x \\
& +\mathbf{B}_{2}^{\mathrm{T}}\left[N_{a}(E A)_{a}+N_{b}(E A)_{b}\right] \mathbf{B}_{2}
\end{aligned}
$$

$4 a$.

$$
\begin{aligned}
\mathbf{B}_{1}= & {\left[0 ;-\frac{6}{L^{2}}+\frac{12 x}{L^{3}} ;-\frac{4}{L}+\frac{6 x}{L^{2}} ; 0 ;\right.} \\
& \left.\frac{6}{L^{2}}-\frac{12 x}{L^{3}} ;-\frac{2}{L}+\frac{6 x}{L^{2}}\right]
\end{aligned}
$$

4b. $\quad \mathbf{B}_{2}=[1 ; 0 ; 0 ; 1 ; 0 ; 0]$ 5b. $\quad N_{b}=\left(\frac{x}{L}\right)$

$\boldsymbol{\delta}$ is the displacement vector; $(E I)_{a}$ and $(E I)_{b}$ are the flexural rigidities, $(E A)_{a}$ and $(E A)_{b}$ are the axial stiffnesses, and $\phi_{\mathrm{r} a}$ and $\phi_{\mathrm{r} b}$ are the residual curvatures with subscripts $a$ and $b$ denoting nodes $a$ and $b$, respectively; $x$ is the $x$-coordinate in the element axial direction; and $L$ is the length of the element. The element length should not exceed the overall depth of section in order to yield accurate results.

The axial stiffnesses $(E A)_{a}$ and $(E A)_{b}$ at nodes $a$ and $b$, respectively, are obtained taking into account the prevailing curvatures there. The axial stiffness is calculated based on a fictitious incremental strain $\Delta \varepsilon$ by the central difference method. First, fictitious uniform strains of $\Delta \varepsilon / 2$ and $-\Delta \varepsilon / 2$ are imposed on the current strain profile that has resulted from the current bending moment and axial force, giving two fictitious strain profiles. From these fictitious strain profiles, two fictitious stress profiles can be worked out together with their associated axial forces. The axial stiffness can then be worked out by dividing the increment in axial force by the increment in length resulting from the fictitious incremental strain $\Delta \varepsilon$.

Elements located within each potential plastic hinge zone are identified and grouped together during discretisation. These elements are assumed to have the same curvature as the element in the group that reaches the moment capacity first. The potential plastic hinge zone is given a suitable length and centred at a point of local peak in the bending moment diagram. As the plastic hinge length may have a marked influence on the subsequent 
variation of moment, parametric studies will be carried out to investigate its effects.

\subsection{Section analysis}

At each element node, several sets of moment-curvature curves with different prescribed mean axial stresses are obtained from section analyses based on the approach of Au et al. (2011), which takes into account material non-linearity and stress path dependence. The constitutive models for concrete and prestressing steel are those proposed by Attard and Setunge (1996) and Menegotto and Pinto (1973), respectively, while non-prestressing steel is assumed to be elastic-plastic. Both the non-prestressed steel and prestressed steel are assumed to be perfectly bonded to the surrounding concrete. An iterative process with the curvature applied incrementally is adopted. At each iteration step, the strain variation is determined assuming that plane sections remain plane after bending, and the concrete and steel stresses are evaluated from their respective constitutive models. Axial equilibrium is used to determine the position of the neutral axis, after which the resisting moment is calculated. This iterative process is repeated until sufficient length of the full-range moment-curvature curve has been obtained.

\subsection{Iteration process}

The analysis starts by forming the element and global stiffness matrices $\mathbf{K}_{\mathrm{e}}$ and $\mathbf{K}_{\mathrm{g}}$, respectively. The cumulative incremental load or displacement is then applied, on which iterations are performed and the residual curvature $\phi_{\mathrm{r}}$ at each element node is updated until a set of admissible displacements and forces at all nodes is obtained. The procedure is explained below focusing on the iteration process at any load step $i$.

(a) Step 1. After determining the nodal displacements and forces from Equation 2, the curvature $\phi_{i}^{n}$ at each element node can be calculated from the element displacement vector $\boldsymbol{\delta}^{n}$ by

\section{6. $\phi_{i}^{n}=\mathbf{B} \boldsymbol{\delta}^{n}$}

where the subscript $i$ and superscript $n$ denote the $i$ th load step and $n$th iteration step, respectively, and $\mathbf{B}$ is the strain matrix obtained by assembling the flexural and axial strain sub-matrices $\mathbf{B}_{1}$ and $\mathbf{B}_{2}$.

(b) Step 2. For each element, determine the mean axial stress $\sigma_{\mathrm{m}}$ in the element. Identify two suitable moment-curvature curves for mean axial stresses $\sigma_{\mathrm{m}}^{1}$ and $\sigma_{\mathrm{m}}^{2}$ such that $\sigma_{\mathrm{m}}^{1} \leqslant \sigma_{\mathrm{m}} \leqslant \sigma_{\mathrm{m}}^{2}$. Obtain moment $M_{i}^{n}$ corresponding to the calculated curvature $\phi_{i}^{n}$ by linear interpolation between the two moment-curvature curves.

(c) Step 3. The moment $m_{i}^{n}$ calculated from the finite-element analysis is checked against the moment $M_{i}^{n}$. If the discrepancy between $m_{i}^{n}$ and $M_{i}^{n}$ falls below a certain tolerance, no updating is necessary. If $m_{i}^{n}$ exceeds $M_{i}^{n}$ by an amount above the tolerance, the residual curvature is updated using $M_{i}^{n}$ by a re-arranged form of Equation 1, namely

$$
\text { 7. }\left(\phi_{\mathrm{r}}\right)_{i}^{n+1}=\phi_{i}^{n}-\frac{M_{i}^{n}}{E I}
$$

where $\left(\phi_{\mathrm{r}}\right)_{i}^{n+1}$ is the updated residual curvature to be used in the next iteration. On the contrary, if $m_{i}^{n}$ is less than $M_{i}^{n}$, then $m_{i}^{n}$ is taken as the updated moment while the residual curvature need not be updated.

(d) Step 4. Calculate the strain distribution corresponding to $\phi_{i}^{n}$ at the nodal points of each element. The method as described in Section 2.2 is used to calculate the new axial stiffnesses from which the stiffness matrices can be updated.

Steps 1-4 are repeated as necessary until the calculated moments and curvatures of each of the elements lies either on the moment-curvature curve in the loading direction or along an unloading path.

The iteration process is further elaborated graphically using the moment-curvature curve shown in Figure 1(a). For ease of explanation, the moment-curvature curve between points A and B is shown enlarged in Figure 1(b). Suppose that the moment and curvature at the beginning of load step $i$ are denoted by point A with residual curvature $\left(\phi_{\mathrm{r}}\right)_{i}$. If the first iteration predicts point 1 with moment $m_{i}^{1}$ and curvature $\phi_{i}^{1}$ such that the moment $m_{i}^{1}$ exceeds the moment $M_{i}^{1}$ at point 2 of the moment-curvature curve by an amount above the tolerance, the residual curvature is updated with a new value $\left(\phi_{\mathrm{r}}\right)_{i}^{1}$. If the second iteration predicts point 3 , which lies on an unloading path, the residual curvature is kept unchanged. Subsequent iterations may yield point 4 and so forth. The process will be terminated as the moment and curvature converge to those at point B. Suppose that on reaching point B, the section undergoes unloading. The moment and curvature of the section will follow the unloading path in Figure 1(a), which is assumed to be parallel to the initial elastic region. The use of initial flexural rigidity $E I$ together with the residual curvature $\phi_{\mathrm{r}}$ has been found to improve convergence, as some elements will sooner or later unload along paths parallel to the initial elastic branches.

\subsection{Configuration of the beam analysed}

The three PC structures as shown in Figure 2 are analysed for their full-range behaviour. The single-span PC beam in case 1, as shown in Figure 2(a), can be considered similar to a typical interior span of a continuous beam. The beam is $12 \mathrm{~m}$ long and is fixed at its left end but restrained against rotation and deflection, while allowing free axial displacement at its right end. The continuous three-span PC beam in case 2 comprises two $9 \mathrm{~m}$ side spans and a $12 \mathrm{~m}$ central span, as shown in Figure 2(b). Figure 2(c) shows that the three-bay frame in case 3 has a similar span configuration except for the interior monolithic RC column supports, and therefore variations in member axial load are expected. The beam and column sections used are shown in 
Engineering and Computational Mechanics Volume 166 Issue EM1
Non-linear analysis and moment redistribution of prestressed concrete members

Leung, Au and Kwan
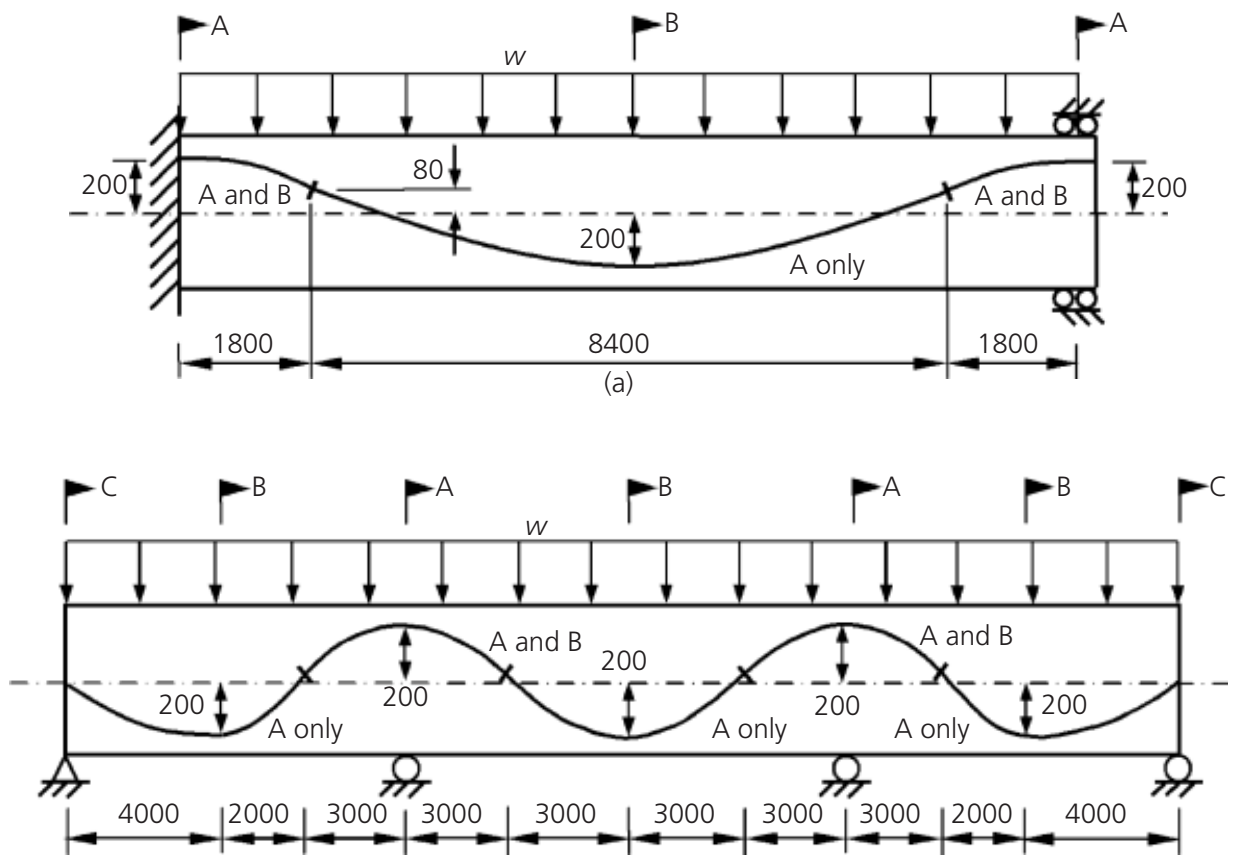

(b)

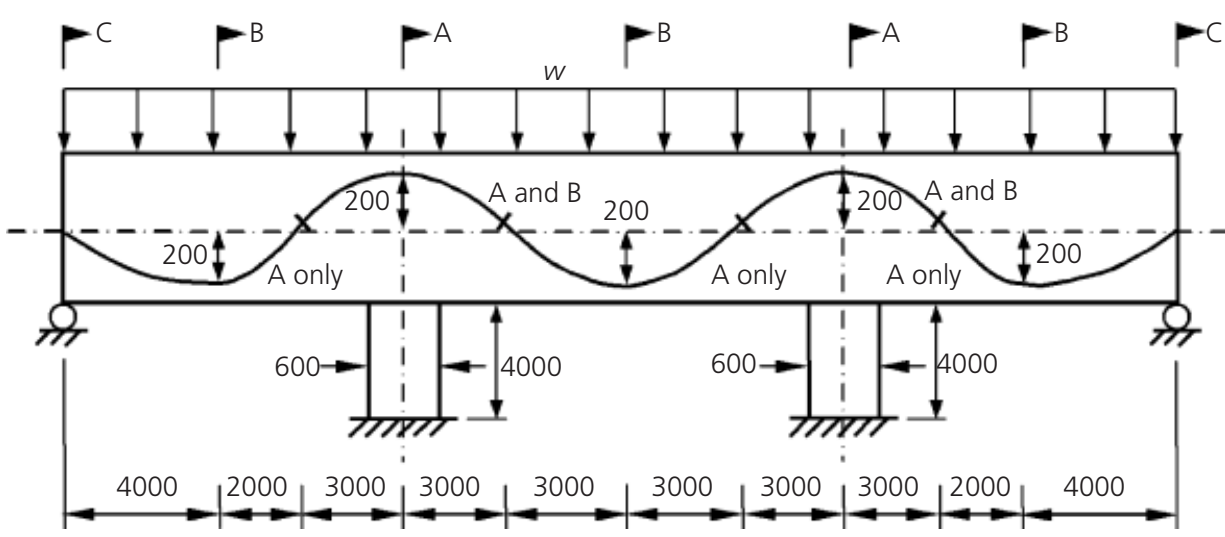

(c)
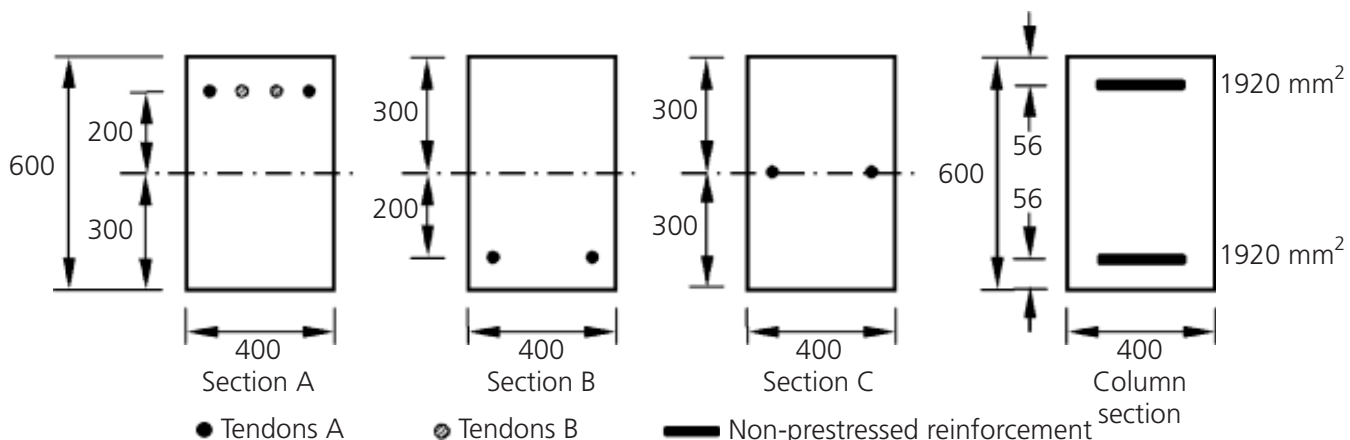

(d)

Figure 2. Configurations of the structures analysed (dimensions in $\mathrm{mm}$, not to scale): (a) case 1, single-span beam; (b) case 2 , three-span beam; (c) case 3, three-bay frame; (d) beam and column sections 
Figure 2(d). The columns in case 3 are so designed that no failure would occur throughout the analysis. The beams are posttensioned by multi-strand tendons having an elastic modulus of $200000 \mathrm{MPa}$ and an ultimate tensile strength of $1860 \mathrm{MPa}$. Two continuous tendons (i.e. tendons A) are provided along the entire length of the beams. Two additional tendons (i.e. tendons B) are provided over an effective distance of $1800 \mathrm{~mm}$ from each end of the single-span beam and over an effective distance of $3000 \mathrm{~mm}$ from each interior support of the three-span beam and three-bay frame in both directions. Each tendon profile consists of a smooth curve made up of parabolic segments, as shown in Figure 2. Concrete having in-situ uniaxial strength of $50 \mathrm{MPa}$ is used for the analysis. The entire length of beam in all cases is subject to a uniformly distributed load, comprising a fixed dead load and an imposed load incrementally added. The amount of prestressing steel is varied to give different values of moment capacity in order to study the effect of moment redistribution.

\section{Moment redistribution of PC members}

In this paper, the prescribed moment redistribution refers to the adjustment of design hogging and sagging moments at the support and mid-span sections, respectively, during the design process. The amount of moment redistribution $\beta$ is defined as the fraction of design elastic moment that is reduced, namely

$$
\text { 8. } \beta=1-\frac{M_{\mathrm{u}}^{\prime}}{M_{\mathrm{u}}}
$$

where $M_{\mathrm{u}}$ is the design moment at a section obtained by elastic analysis before redistribution is prescribed, and $M_{\mathrm{u}}^{\prime}$ is the design moment at the section after redistribution is prescribed. Moment redistribution in PC members is prescribed by adjusting the steel content. In view of the limited ductility of PC sections and taking into account the overall structural behaviour, there may be an amount of reduction $\gamma$ in load-carrying capacity defined as

9. $\quad \gamma=1-\frac{P_{\mathrm{u}}^{\prime}}{P_{\mathrm{u}}}$

where $P_{\mathrm{u}}^{\prime}$ and $P_{\mathrm{u}}$ are the load-carrying capacities of the beam designed with and without prescribed moment redistribution, respectively.

\section{Plastic hinge length}

The plastic hinge lengths of RC and PC members have long been controversial. Mendis (2001) and Deng et al. (2001) found the empirical formulae for calculating plastic hinge length largely inconsistent. Deng et al. (2001) gave an example in which the plastic hinge length of a series of beams calculated using the formula proposed by Baker (1956) ranged from $0 \cdot 4 d$ to $2 \cdot 4 d$, that proposed by Mattock (1967) ranged from $0 \cdot 7 d$ to $1 \cdot 125 d$, and that proposed by Sawyer (1964) ranged from $0 \cdot 55 d$ to $1 \cdot 19 d$. As part of a structural member reaches the plastic state during loading to destruction, deformation is concentrated at the plastic hinges. Within the plastic hinge length, the curvature is often assumed to increase beyond the value associated with the peak moment and follow the post-peak branch of moment-curvature curve. Elsewhere, the member may unload as the resistance drops. The plastic hinge length is closely related to rotational capacity there, both of which affect not only the load-carrying capacity but also the ductility or deformability of the structure. The effects of plastic hinge length on the reduction in load-carrying capacity as a result of prescribed moment redistribution are examined below.

\section{Parametric studies}

Parametric studies are performed to investigate the behaviour of PC members of different configurations and with different amounts of moment redistribution $\beta$. The non-linear variation of moment along the member over the entire loading history is also examined to study the structural behaviour at different load levels. The relationship between the reduction in load-carrying capacity $\gamma$ and the amount of prescribed moment redistribution $\beta$ will be studied focusing on the effects of the ratio of neutral axis depth $x$ to effective depth $d$ at moment capacity, which is ultimately related to the section deformability and the plastic hinge length $l_{\mathrm{p}}$.

The models used in each case are divided into four groups, namely groups 1 to 4 with assumed plastic hinge lengths of $0 \cdot 8 d, 1 \cdot 0 d, 1 \cdot 2 d$ and $1.4 d$, respectively. In each group, four series of models of increasing amounts of prestressing steel and hence increasing moment capacities are investigated. For each series, there is a reference configuration on which prescribed moment redistribution of up to $20-25 \%$ is imposed. Relevant parameters are varied over the expected ranges. Figure 3 shows the finite-element meshes used. Non-linear analysis is carried out to obtain the structural response and the ranges of $x / d$ ratios at the support sections. Details and results of the models investigated are summarised in Table 1.

\subsection{Moment variation in PC members}

The single-span beam having $l_{\mathrm{p}}$ of $1 \cdot 0 d$ (group 2) and $A_{\mathrm{ps}}$ of series 4 with prescribed moment redistribution of $10 \%$ is further studied. In particular, the moments at the support and mid-span sections of the span of length $l$ with increase in imposed load $w$ and mid-span displacement up to failure are monitored. Figure 4 shows the ratio of change in bending moment $\Delta M$ to the change in imposed load expressed as $\Delta w l^{2}$ plotted against the imposed load $w$. For imposed load below $8 \mathrm{kN} / \mathrm{m}$, the values of $\Delta M /\left(\Delta w l^{2}\right)$ for the support and mid-span sections are obviously close to the elastic values of $1 / 12$ and $1 / 24$, respectively. As the imposed load further increases and non-linear behaviour becomes more significant, the support moment increases slightly faster while the midspan moment increases at a slower rate, which clearly illustrates the variation of moment prior to failure of the beam. The beam approaches its ultimate state as loading reaches $60 \mathrm{kN} / \mathrm{m}$. As the support section has reached its moment capacity, it cannot resist much further increase in moment, thereby causing a drop of the curve. This is accompanied by a steep climb of the curve for midspan moment with any further increase in imposed displacement. 


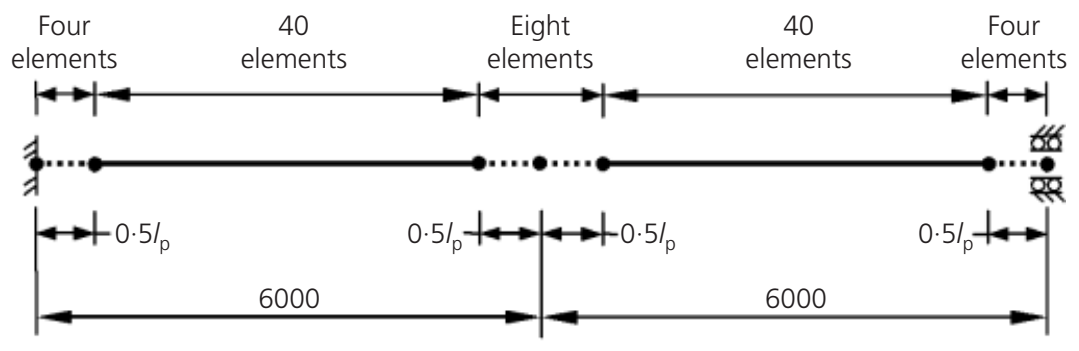

........ Plastic hinge region

(a)

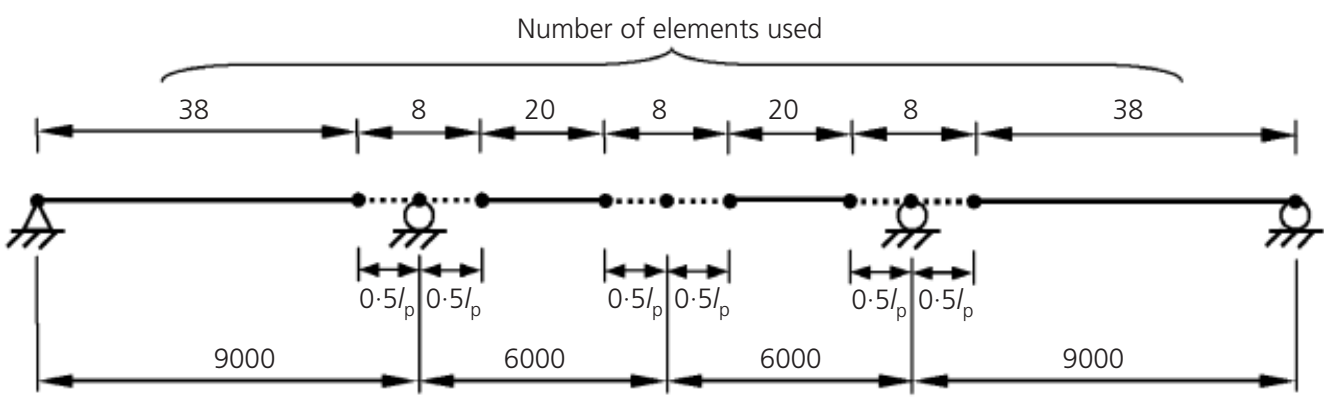

(b)



(c)

Figure 3. Finite-element meshes for structural analysis

(dimensions in $\mathrm{mm}$, not to scale): (a) case 1, single-span beam;

(b) case 2, three-span beam; (c) case 3, three-bay frame

The ratio of moment $M$ to the corresponding moment capacity $M_{\mathrm{p}}$ is plotted against the mid-span displacement in Figure 5 for both the support and mid-span sections. Because of the reduced moment capacity at support attributable to the prescribed moment redistribution of $10 \%$, the moment capacities at support sections are first reached roughly at a mid-span displacement of $0.055 \mathrm{~m}$, leading to earlier formation of plastic hinges there. In view of the limited ductility at the support sections, they experience a drop in moment at the post-peak stage while the mid-span moment continues increasing. Once the mid-span section reaches its moment capacity, the beam can be considered to have become a mechanism, as all three plastic hinges have reached their postpeak branches. Unlike the classical plastic theory of structures that assumes perfect plasticity and unlimited ductility, PC sections with limited ductility suffer from declining moment resistance after reaching the moment capacity. This explains why the prescribed moment redistribution reduces the load-carrying capacity.

\subsection{Reduction in load-carrying capacity}

The variation of reduction in load-carrying capacity $\gamma$ with respect to the change in prescribed moment redistribution $\beta$ is examined for all the models analysed. As the results for the 


\begin{tabular}{|c|c|c|c|c|c|}
\hline \multirow[t]{2}{*}{ Case } & \multirow[t]{2}{*}{ Group $\left(I_{p}\right)$} & \multirow[t]{2}{*}{ Series } & \multicolumn{2}{|c|}{$A_{p s}$ of reference configuration: $\mathrm{mm}^{2}$} & \multirow[t]{2}{*}{$x / d\left(\right.$ see notes $\left.{ }^{a, b}\right)$} \\
\hline & & & Section A & Section B & \\
\hline \multirow[t]{4}{*}{ Case 1: single-span beam } & 1 to 4 & 1 & 783 & 569 & $0 \cdot 19-0.14$ \\
\hline & $(0 \cdot 8 d$ to $1 \cdot 4 d)$ & 2 & 958 & 442 & $0 \cdot 23-0.17$ \\
\hline & & 3 & 1143 & 522 & $0.27-0.20$ \\
\hline & & 4 & 1345 & 604 & $0.32-0.23$ \\
\hline \multirow[t]{4}{*}{ Case 2: three-span beam } & 1 to 4 & 1 & 738 & 405 & $0 \cdot 18-0 \cdot 14$ \\
\hline & $(0 \cdot 8 d$ to $1 \cdot 4 d)$ & 2 & 902 & 492 & $0 \cdot 22-0.17$ \\
\hline & & 3 & 1073 & 583 & $0 \cdot 26-0.20$ \\
\hline & & 4 & 1257 & 674 & $0.30-0.23$ \\
\hline \multirow[t]{4}{*}{ Case 3: three-bay frame } & 1 to 4 & 1 & 738 & 405 & $0 \cdot 18-0.14$ \\
\hline & $(0 \cdot 8 d$ to $1 \cdot 4 d)$ & 2 & 902 & 492 & $0 \cdot 22-0.17$ \\
\hline & & 3 & 1073 & 583 & $0 \cdot 26-0.20$ \\
\hline & & 4 & 1257 & 674 & $0.30-0.23$ \\
\hline
\end{tabular}

a The left limit is the $x / d$ ratio of section $A$ of the reference configuration.

${ }^{b}$ The right limit is the $x / d$ ratio of section $A$ of the configuration with the maximum prescribed moment redistribution applied in the corresponding series.

Table 1. Various groups and series of models considered in parametric studies

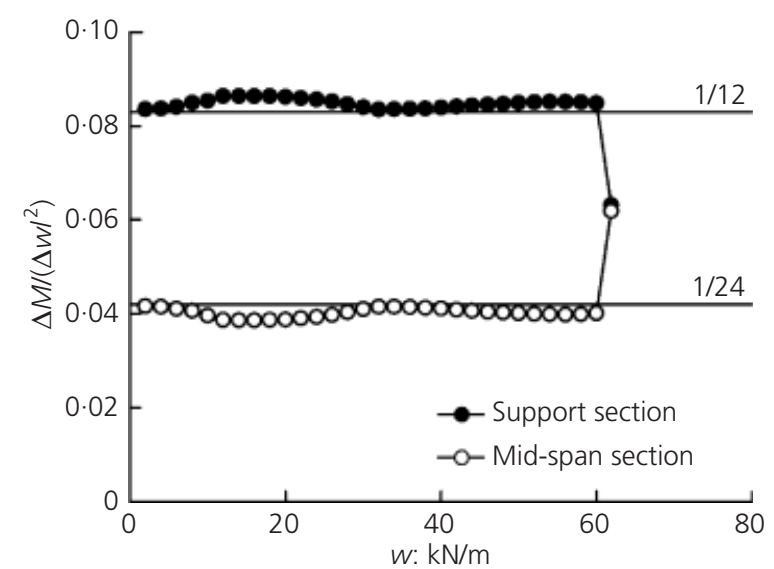

Figure 4. Variation of moments at support and mid-span sections of single-span beam with increasing load (group 2, series 4 and $\beta=10 \%$ )

three-span beam and three-bay frame are similar, only those for the single-span beam and three-span beam are presented in Figures 6 and 7, respectively. Also shown are the results for all series with different amounts of prestressing steel, which are associated with different $x / d$ ratios at moment capacity of the support section. Apart from confirming that the reduction in loadcarrying capacity $\gamma$ increases with the prescribed moment redistribution $\beta$, they also show that those with higher amounts of prestressing steel, and hence higher $x / d$ ratios at moment capacity or lower deformability, suffer more reduction in load-carrying capacity. The results for the three-span beam and three-bay frame

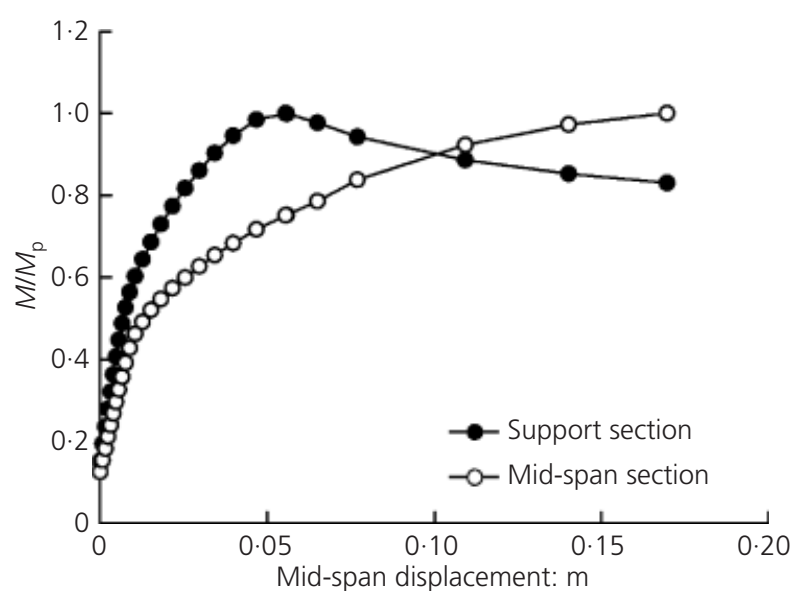

Figure 5. Variation of moments with increasing mid-span displacement of single-span beam (group 2, series 4 and $\beta=10 \%$ )

with $l_{\mathrm{p}}$ of $1.2 d$ are presented together in Figure 8. Apart from confirming the same trend observed before, they also show that the effects of support conditions and axial load on the reduction in load-carrying capacity are insignificant.

To gain more insight, regression analysis is performed to obtain empirical formulae that relate $\gamma$ to $\beta$ and $x / d$, namely

10. $\gamma=\left[\lambda_{1}\left(x / d+\lambda_{3}\right)^{m}+\lambda_{2}\right] \beta^{n}$ 
Non-linear analysis and moment redistribution of prestressed concrete members

Leung, Au and Kwan

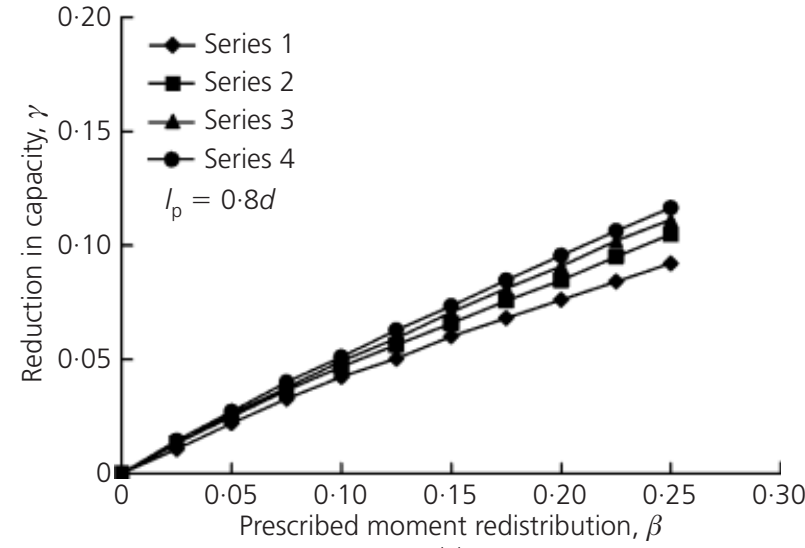

(a)

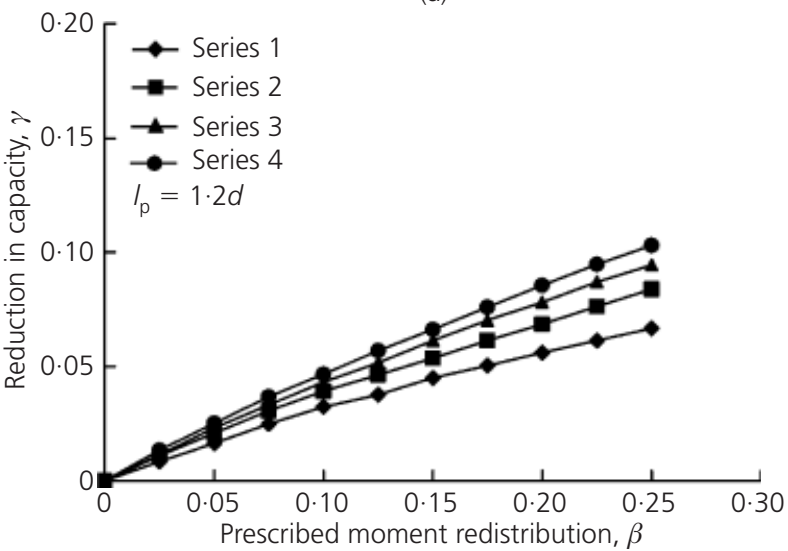

(b)

Figure 6. Reduction in load-carrying capacity of single-span beam with various plastic hinge lengths: (a) plastic hinge length of $0.8 d$; (b) plastic hinge length of $1 \cdot 2 d$

where $\lambda_{1}, \lambda_{2}, \lambda_{3}, m$ and $n$ are parameters determined by regression from the datasets of $\gamma$ and $\beta$ corresponding to each group of beam models with different plastic hinge lengths $l_{\mathrm{p}}$ assumed. Since the results for the three-span beam and three-bay frame are largely similar, only those for the single-span beam and three-span beam are presented. The parameters for Equation 10 determined for various plastic hinge lengths $l_{\mathrm{p}}$ are given in Table 2. Good correlation between the values of $\gamma$ determined by regression and those obtained from the non-linear analyses is observed, with $R^{2}$ values above $0 \cdot 96$. With the empirical formulae developed, the reduction in load-carrying capacity $\gamma$ can be predicted from the prescribed moment redistribution $\beta$ and the $x /$ $d$ ratio at moment capacity. It can be shown that the empirical formulae also apply to beams of the same materials having the same geometric proportions of dimensions in the vertical, longitudinal and transverse directions.

\subsection{Effects of $x / d$ at moment capacity of support section}

It is generally acknowledged that the ability of a concrete section to undergo plastic deformation is reflected by the $x / d$ ratio at moment capacity. Codes of practice often adopt the maximum

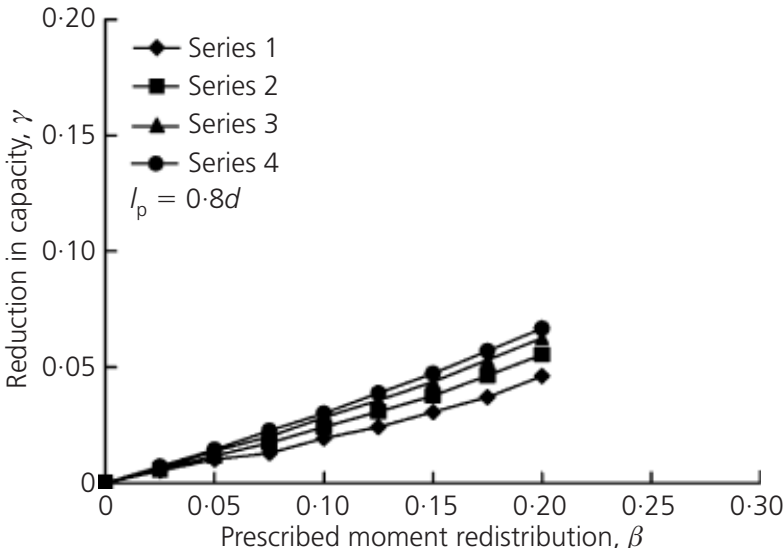

(a)

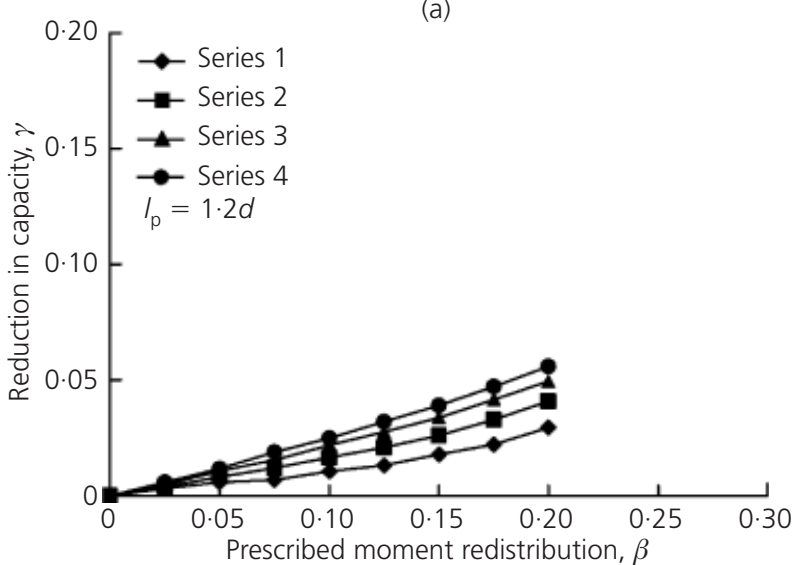

(b)

Figure 7. Reduction in load-carrying capacity of three-span beam with various plastic hinge lengths: (a) plastic hinge length of $0 \cdot 8 d$; (b) plastic hinge length of $1 \cdot 2 d$

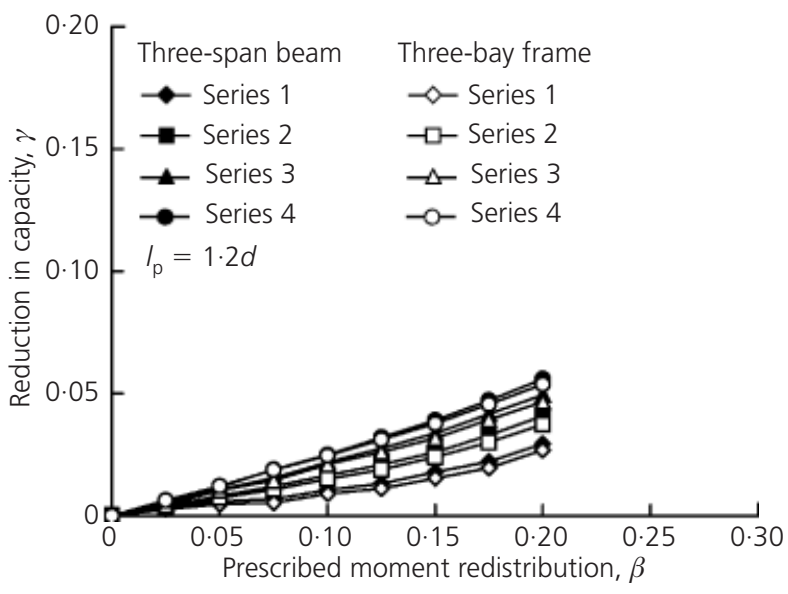

Figure 8. Reduction in load-carrying capacity of three-span beam and three-bay frame with plastic hinge length of $1 \cdot 2 d$

allowable $x / d$ ratio to stipulate the minimum ductility required for concrete sections. It is therefore desirable to examine the effects of $x / d$ ratio on the reduction in load-carrying capacity $\gamma$ under different prescribed moment redistribution $\beta$. The effects of $x / d$ 


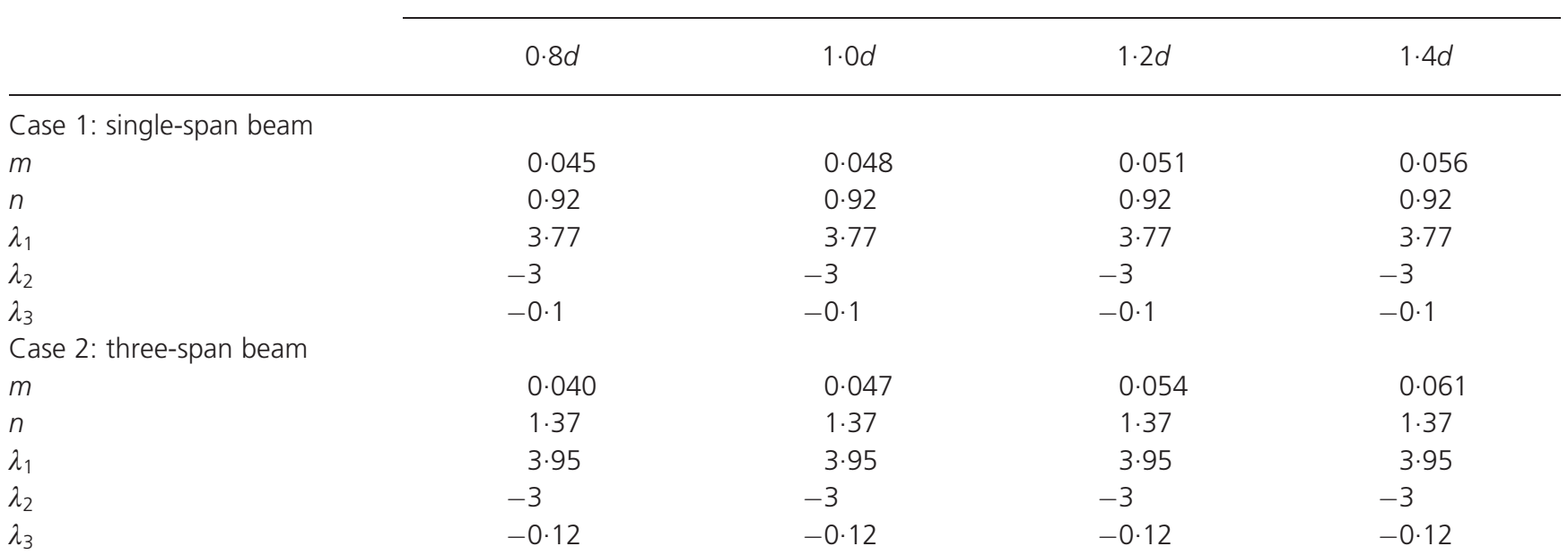

Table 2. Parameters in Equation 10 for different plastic hinge lengths

ratio for the single-span beam models with assumed plastic hinge lengths $l_{\mathrm{p}}$ of $0.8 d$ and $1.4 d$ are illustrated in Figures 9(a) and 9(b), respectively, while those for the three-span beam are shown in Figures 10(a) and 10(b), respectively. The results show that as the $x / d$ ratio increases, which implies that the section relies more on compression and becomes less deformable, there is higher reduction in load-carrying capacity under prescribed moment redistribution. Examining results from Figures 9 and 10, especially focusing on the spacing between curves, it is noted that a higher plastic hinge length tends to amplify the effect of $x / d$ ratio at moment capacity on the reduction in load-carrying capacity $\gamma$.

It is worthwhile to notice from results for the single-span beam and three-span beam that, with $25 \%$ moment redistribution prescribed, reduction in load-carrying capacity can reach $10-15 \%$ with support sections having relatively high $x / d$ ratio at moment capacity of $0 \cdot 45$. As the support sections become more deformable with lower $x / d$ ratio at moment capacity of $0 \cdot 15$, reduction in load-carrying capacity can be reduced to $5 \%$ or less when the same amount of moment redistribution is prescribed.

\subsection{Effects of plastic hinge length $I_{\mathrm{P}}$}

The effects of plastic hinge length $l_{\mathrm{p}}$ on the relationship between reduction in load-carrying capacity $\gamma$ and the prescribed moment redistribution $\beta$ are examined. The results for $x / d$ ratios of 0.45 and $0 \cdot 15$ at moment capacity of the support section are presented in Figures 11(a) and 11(b), respectively, for the single-span beam, and Figures 12(a) and 12(b), respectively, for the three-span beam. Results in Figures 11(a) and 12(a), which correspond to beams with support sections of higher $x / d$ ratio at moment capacity and hence lower deformability, show that the curves tend to merge together. However, Figures 11(b) and 12(b) show that, as the support sections become more deformable, which correspond to lower $x / d$ ratio at moment capacity, the increase in slope



(a)

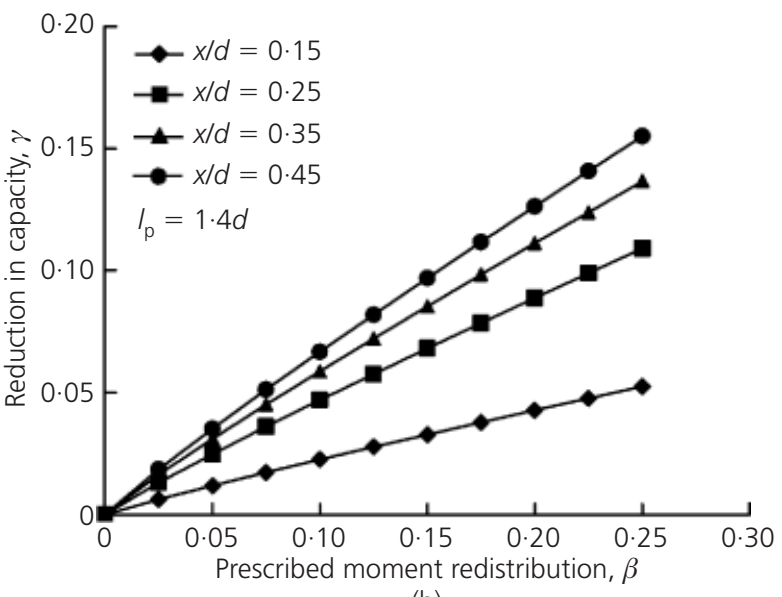

(b)

Figure 9. Effects of $x / d$ ratio at moment capacity on reduction in load-carrying capacity of single-span beam: (a) plastic hinge length of $0.8 d$; (b) plastic hinge length of $1.4 d$ 
Non-linear analysis and moment redistribution of prestressed concrete members

Leung, Au and Kwan

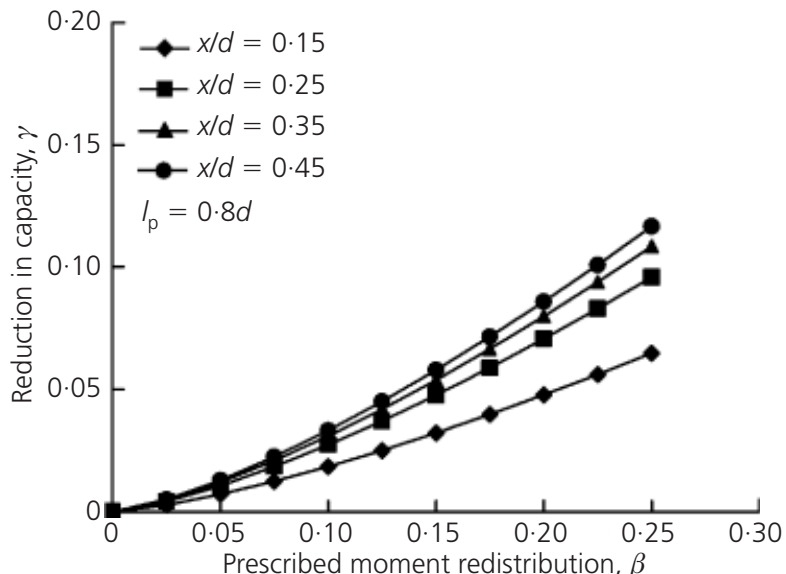

(a)

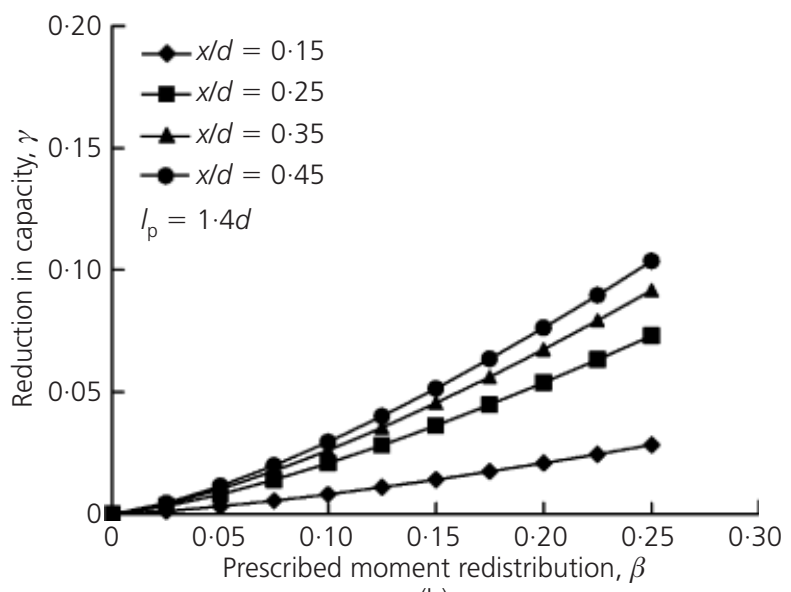

(b)

Figure 10. Effects of $x / d$ ratio at moment capacity on reduction in load-carrying capacity of three-span beam: (a) plastic hinge length of $0.8 d$; (b) plastic hinge length of $1.4 d$

of the curves is more significant as the plastic hinge length $l_{\mathrm{p}}$ decreases. In other words, with higher deformability at the support sections, the plastic hinge length $l_{\mathrm{p}}$ will have greater impact on the reduction in load-carrying capacity $\gamma$ under prescribed moment redistribution $\beta$.

\section{Design recommendations}

It has been shown that the reduction in load-carrying capacity $\gamma$ in $\mathrm{PC}$ members under prescribed moment redistribution $\beta$ depends on the deformability, which is reflected by the $x / d$ ratio at moment capacity of the support sections, as well as the plastic hinge length $l_{\mathrm{p}}$. In general, to avoid substantial reduction in loadcarrying capacity, it is essential that the support sections within the potential plastic hinge zones are sufficiently deformable so that favourable variation of moment can take place on application of loading.

In view of the moment-curvature properties of PC sections, such members are inherently less ductile than $\mathrm{RC}$ members that are

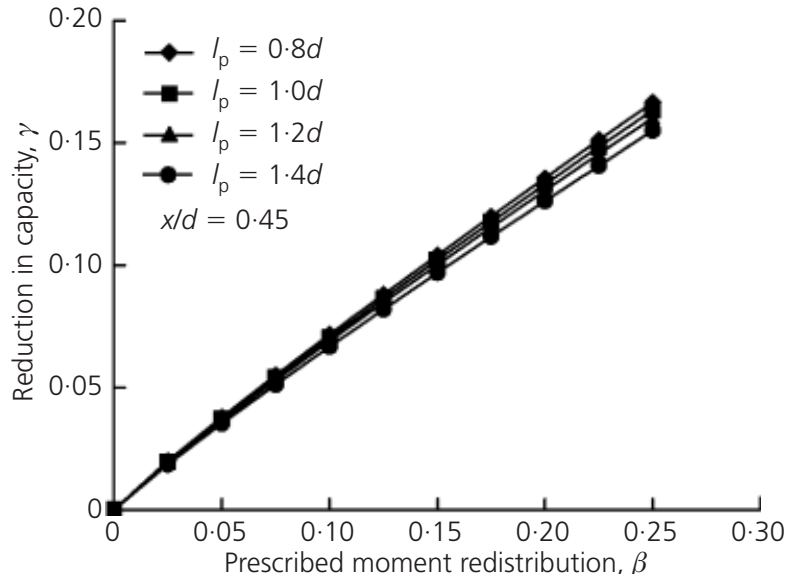

(a)

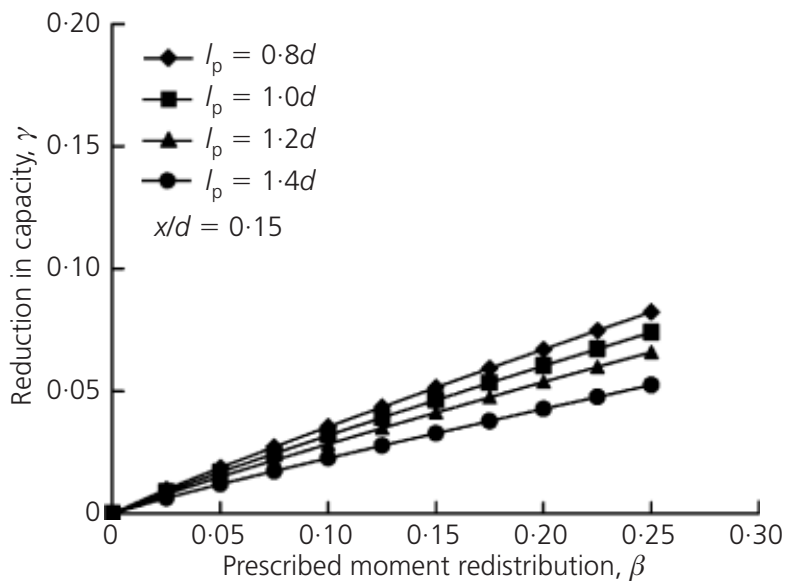

(b)

Figure 11. Effects of plastic hinge length on reduction in loadcarrying capacity of single-span beam for various $x / d$ ratios at moment capacity: (a) $x / d=0.45$; (b) $x / d=0.15$

lightly reinforced. Once the load-carrying capacity of a PC member is reached, its resistance starts to drop. Therefore a logical way of ensuring the safety while prescribing moment redistribution is to perform non-linear analysis to examine its effects on load-carrying capacity.

\section{Conclusions}

The effects of prescribed moment redistribution on PC members are investigated using full-range, non-linear, finite-element analyses. Owing to the limited ductility of PC sections, the loadcarrying capacity of the member is always reduced by prescribed moment redistribution during design. A parametric study has been carried out with some typical structural configurations to examine the relationship between the prescribed moment redistribution and the reduction in load-carrying capacity, and how this relationship is affected by the deformability of the support section and the plastic hinge length.

Under prescribed moment redistribution of up to $25 \%$, up to $15 \%$ 
Non-linear analysis and moment redistribution of prestressed concrete members

Leung, Au and Kwan



(a)

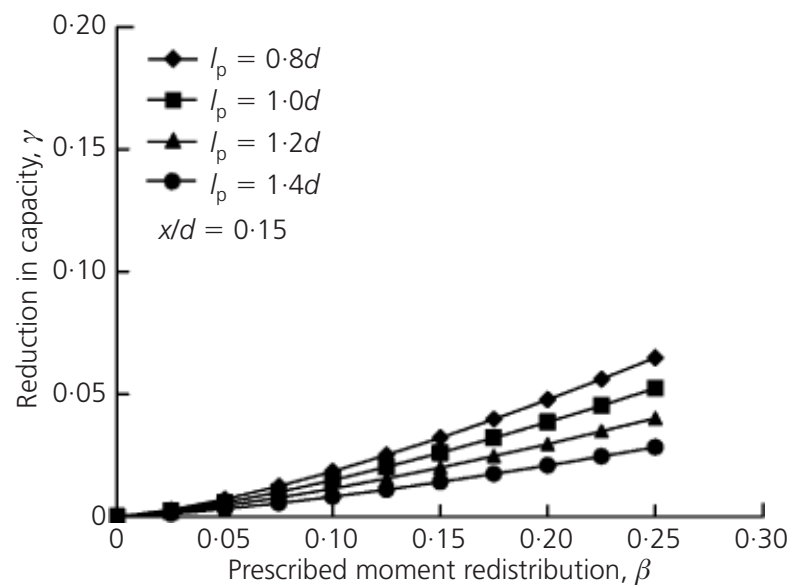

(b)

Figure 12. Effects of plastic hinge length on reduction in loadcarrying capacity of three-span beam for various $x / d$ ratios at moment capacity: (a) $x / d=0.45$; (b) $x / d=0.15$

reduction in load-carrying capacity is observed for members with less deformable support sections having $x / d$ ratio at moment capacity of $0 \cdot 45$. However, if the support section has $x / d$ ratio at moment capacity of $0 \cdot 15$ and is more deformable, the reduction in load-carrying capacity drops substantially to approximately $5 \%$. Therefore, due care should be exercised to ensure that the support sections are sufficiently deformable when prescribing the maximum allowable moment redistribution of $20 \%$.

The plastic hinge length has a critical effect on the reduction in load-carrying capacity, especially for members with support sections having high deformability. For those with support sections having relatively low deformability, however, the effect of plastic hinge length on reduction in load-carrying capacity is insignificant.

\section{Acknowledgements}

The study undertaken is supported by the Research Grants Council of the Hong Kong Special Administrative Region, China (RGC Project No. HKU 710807E), and the Committee on
Research and Conference Grants and the HKU SPACE Research Fund, The University of Hong Kong, Hong Kong, China.

\section{REFERENCES}

ACl (American Concrete Institute) (2005) Building Code Requirements for Reinforced Concrete (ACI 318-05) and Commentary (ACI 318-R-05). ACI Committee 318, ACI, Farmington Hills, MI, USA.

Attard MM and Setunge S (1996) The stress strain relationship of confined and unconfined concrete. ACI Materials Journal 93(5): $432-442$.

Au FTK, Leung CCY and Kwan AKH (2011) Flexural ductility and deformability of reinforced and prestressed concrete sections. Computers and Concrete 8(4): 473-489.

Baker ALL (1956) Ultimate Load Theory Applied to the Design of Reinforced and Prestressed Concrete Frames. Concrete Publications Ltd, London, UK.

BSI (2004) BS EN 1992-1-1:2004. Design of concrete structures. General rules and rules for buildings. BSI, London, UK.

Campbell TI and Kodur VKR (1990) Deformation controlled nonlinear analysis of prestressed concrete continuous beams. $P C I$ Journal 35(5): 42-55.

Cohn MZ and Riva P (1992) Yield safety, cracking control, and moment redistribution. Journal of Structural Engineering 118(2): 447-468.

Concrete Design Committee (1995) Concrete structures standard. Standards New Zealand, Wellington, New Zealand.

CSA Technical Committee on Reinforced Concrete Design (1994) A23.3-94: Design of concrete structures. Canadian Standards Association, Rexdale, Canada.

Deng L, Ghosn M, Znidaric A and Casas JR (2001) Nonlinear flexural behavior of prestressed concrete girder bridges. Journal of Bridge Engineering 6(4): 276-284.

do Carmo RNF and Lopes SMR (2005) Ductility and linear analysis with moment redistribution in reinforced highstrength concrete beams. Canadian Journal of Civil Engineering 32(1): 194-203.

do Carmo RNF and Lopes SM (2006) Required plastic rotation of $\mathrm{RC}$ beams. Proceedings of the Institution of Civil Engineers - Structures and Buildings 159(2): 77-86.

Lopes SMR, Harrop J and Gamble AE (1997) Study of moment redistribution in prestressed concrete beams. Journal of Structural Engineering 123(5): 561-566.

Mattock AH (1959) Redistribution of design bending moments in reinforced concrete continuous beams. Proceedings of the Institution of Civil Engineers 13(1): 35-46.

Mattock AH (1967) Discussion of 'Rotational capacity of reinforced concrete beams' by W. G. Corley. Journal of the Structural Division 93(ST2): 519-522.

Mendis P (2001) Plastic hinge lengths of normal and high strength concrete in flexure. Advances in Structural Engineering 4(4): 189-195.

Menegotto M and Pinto PE (1973) Method of analysis for cyclically loaded R.C. plane frames. IABSE Preliminary Report for Symposium on Resistance 
and Ultimate Deformability of Structures Acted on by Well-Defined Repeated Loads, Lisbon, pp. 15-22.

Priestley MJN and Park R (1972) Moment redistribution in continuous prestressed concrete beams. Magazine of Concrete Research 24(80): 157-166, http://dx.doi.org/10.1680/ macr.1973.24.80.157.
Sawyer HA (1964) Design of concrete frames for two failure states. Proceedings of the International Symposium on Flexural Mechanics of Reinforced Concrete, Miami, pp. 405-431.

Scott RH and Whittle RT (2005) Moment redistribution effects in beams. Magazine of Concrete Research 57(1): 9-20, http:// dx.doi.org/10.1680/macr.2005.57.1.9.

\section{WHAT DO YOU THINK?}

To discuss this paper, please email up to 500 words to the editor at journals@ice.org.uk. Your contribution will be forwarded to the author(s) for a reply and, if considered appropriate by the editorial panel, will be published as a discussion in a future issue of the journal.

Proceedings journals rely entirely on contributions sent in by civil engineering professionals, academics and students. Papers should be $2000-5000$ words long (briefing papers should be 1000-2000 words long), with adequate illustrations and references. You can submit your paper online via www.icevirtuallibrary.com/content/journals, where you will also find detailed author guidelines. 